2015-01-14

\title{
Men's Mental Health: A Call to Social Workers
}

\author{
Kevin Shafer \\ Brigham Young University - Provo, kshafer@byu.edu \\ Douglas Wendt \\ Brigham Young University - Provo
}

Follow this and additional works at: https://scholarsarchive.byu.edu/facpub

Part of the Gender and Sexuality Commons, Medicine and Health Commons, and the Other Sociology Commons

\section{Original Publication Citation}

Shafer, K. \& Wendt, D.* (2015). “Men's Mental Health: A Call to Social Workers." Social Work, 60(2): 105-112.

\section{BYU ScholarsArchive Citation}

Shafer, Kevin and Wendt, Douglas, "Men's Mental Health: A Call to Social Workers" (2015). Faculty Publications. 4403.

https://scholarsarchive.byu.edu/facpub/4403

This Peer-Reviewed Article is brought to you for free and open access by BYU ScholarsArchive. It has been accepted for inclusion in Faculty Publications by an authorized administrator of BYU ScholarsArchive. For more information, please contact ellen_amatangelo@byu.edu. 


\title{
Men's Mental Health: A Call to Social Workers
}

\author{
Kevin Shafer and Douglas Wendt
}

\begin{abstract}
Substantial attention is paid to the mental health needs of women and children by social work researchers, educators, and practitioners - and with good reason, as these are two vulnerable populations in U.S. society. However, the status of men's mental health; its resulting effect on individuals, families, and communities; and the various challenges associated with it are often overlooked by social workers. The authors document the prevalence of common mental health issues among men in the United States, the unique problems that men face, and help-seeking behaviors. They also discuss how social work is in an exceptional position to help men, and the systemic effects that social work practice with men can have. The authors assert that helping improve men's mental health is critical for social work, particularly given its values recognizing the dignity and worth of all individuals. Their goal is to raise awareness and spark an open dialogue about social work practice with men.
\end{abstract}

KEY WORDS: gender; help seeking; masculinity; mental health; social work

" his year thousands of men will die from stubbornness," reads a billboard produced by the Agency for Healthcare Research and Quality, a division of the U.S. Department of Health and Human Services (HHS). If we were to rephrase this message to focus on mental health, the board might read, "This year thousands of men will die from untreated mental illness." Although most often the consequences are not lethal, many men across the United States will suffer unnecessarily from treatable mental health disorders such as depression, anxiety, posttraumatic stress disorder (PTSD), various personality disorders, and many other mental health issues (Addis, 2008). It is estimated that more than half of men with diagnosable psychiatric disorders will receive no formal assistance (that is, mental health counseling) or even informal assistance (that is, from friends and family) for their respective problems (Addis \& Mahalik, 2003). Thus, tragically, many men suffer from mental health problems for which they desperately need professional assistance (Addis, 2011). These challenges exist in part because men are often socialized into certain "masculine" views that discourage seeking help. Many men report feeling that helping professionals are ill equipped to improve their mental health, and they see poor mental health as a state of being common to men that cannot be improved. As we will show in this article, there is substantial evidence to suggest that the current state of mental health for men is an important public health issue.
Although men face unique mental health challenges, it is imperative to note that many men occupy privileged positions within society. Patriarchal family structures, the disproportionate political power held by men, and the feminization of poverty are only a few examples of the widespread institutional and societal discrimination that women face. Given social work's emphasis on those groups who suffer from gendered discrimination, it is certainly understandable that researchers, educators, and practitioners have not gravitated to researching men as a special group. Although men are advantaged and privileged in many ways, they have their own unique challenges and difficulties - including poor mental health - that can lead to a lack of selfdetermination, self-worth, and dignity (Furman, 2013). Poor mental health among men can be costly for individuals, families, and communities. Simply put, mental health is a public health concern and ignoring the unique problems and concerns of half the population is problematic and potentially dangerous. As we noted earlier, many mental health issues in men are coupled with an increased risk of alcohol or drug abuse, anger, physically or emotionally abusive behavior, and successful suicide attempts (NIMH, 2005). To be more specific, men are much more likely to be violent with their intimate partners, and mental health problems may be a prominent cause of victimizing others (Acevedo, Lowe, Griffin, \& Botvin, 2013). More generally, the consequences of substance abuse, physical abuse, 
suicide, and other behaviors for women and children have been clearly articulated in the various literatures on these topics. Failing to account for the differences in male manifestations of mental health problems, particularly depression and anxiety, may contribute to the substantial under- and misdiagnosis of mental health issues in men (Connell \& Messerschmidt, 2005; Rochlen et al., 2010).

As we will discuss in the next section, men experience substantial unmet mental health needs. Some critics suggest that social work is more focused on women than men or that the profession adheres too strongly to a medical model that minimizes a gendered perspective on mental health issues (Addis, 2008). To be fair, social workers are currently engaged with certain groups of men. Social work research and clinical work has addressed the needs of men in the military, marginalized racial and ethnic groups, and sexual minorities (Furman, 2013). However, other male populations also merit special attention from social workers, particularly given the profession's value of dignity and respect for all people. In emphasizing the unique contributions, strengths, and challenges of men, Furman (2013) wrote that

many men need help, and . . social workers that do not treat men with empathy, respect, and dignity may fail to prevent or resolve many of the most severe social problems that social workers are dedicated to ameliorating. (pp. 6-7)

The well-being of men is inherently connected to the well-being of women and children because women and children are so often affected by the actions of their fathers, brothers, friends, husbands, and partners. Thus, social work practice with men not only affects individuals, but also can produce positive systemic effects (Bellamy, 2009).

The goal of this article is to illustrate that the discipline's unique adherence to the principles of social justice and the dignity and worth of each individual should lead social workers to be concerned about men's mental health. Furthermore, the professional settings in which social workers are employed, such as the child welfare system and other social services, position them to help men in ways that other helping professionals cannot. In the following sections we will discuss the prevalence of, sources of, and clinical issues associated with men's mental health problems; discuss how and why social workers should engage with men as a special population; and raise a few clinical and research questions regarding men's mental health.

\section{MEN'S MENTAL HEALTH}

\section{Prevalence}

The relationship between gender and mental health is a complex one. Overall, research suggests that, although women are more likely than men to have poor mental health, the size of the mental health gender gap varies by demographic characteristics, such as race or ethnicity and age. For example, gender differences in mental health that exist in nationally representative samples tend to disappear in studies of homogeneous groups, such as those among a particular racial-ethnic group (Piccinelli \& Wilkinson, 2000). Similarly, the reliably higher rates of depression among pubescent girls, emerging adult women, and adult women are not present in early adolescence - a stage during which boys are more likely to be depressed (Piccinelli \& Wilkinson, 2000). These results suggest that an overly simplistic view of the link between mental health and gender is problematic. Girls and women are not more likely to experience mental health conditions than boys and men in all contexts or for all diagnoses.

Most research on gender differences in mental health has addressed depression and anxiety (Parker $\&$ Brotchie, 2010). This is due to the ease of measuring symptoms for these disorders with standardized instruments-even in large-scale, nationally representative data sets (Mossakowski, 2013). Overall, the majority of studies on depression and anxiety show that women are more likely than men to meet clinical criteria for major depressive disorder (MDD), dysthymia, and seasonal affective disorder; no gender difference has been found for bipolar disorders (Piccinelli \& Wilkinson, 2000). Lifetime incidence rates of depression in men are roughly half that in women (Parker \& Brotchie, 2010), and women are more likely than men to experience nearly all anxiety disorders (McLean, Asnaani, Litz, \& Hofmann, 2011). One exception on this latter point is social anxiety disorder, where no gender differences are apparent. Despite the somewhat higher prevalence of common mental health issues in women, a substantial number of men experience adverse mental health conditions. For example, more than one in 10 men will experience a major depressive episode in their lifetime 
(Parker \& Brotchie, 2010). Furthermore, some researchers and commenters have noted that the rates of undiagnosed depression and anxiety in men far surpass those in women-suggesting that the estimated prevalence of mood and anxiety disorders in men is conservative. Thus, we suggest that it is critical for all social workers to recognize how mental health issues in men are similar to and different from those in women.

For some mental health issues, no gender differences have been found. For example, although men with schizophrenia tend to express the symptoms earlier than their female counterparts (Piccinelli \& Homen, 1997), there are no gender differences in its lifetime prevalence (Hendrick, Altschuler, Gitlin, Delrahim, \& Hammen, 2000). Men, however, are more likely to experience other challenges — such as substance abuse and antisocial behaviors (Eaton, Chen, \& Bromet, 2011). The World Health Organization (2007) estimates suggest that nearly one in five men will experience alcohol dependence, while the comparable number is one in 12 for women. What these figures highlight is the need for a more nuanced approach to mental health that recognizes the unique struggles and difficulties that many men share.

The impact of these challenges, which are often rooted in deeper mental health issues, such as mood and anxiety disorders, is clear. Men who abuse alcohol and exhibit antisocial behaviors show little affection toward their partners, are more critical, communicate infrequently, and are dissatisfied with their relationships. Infant children of fathers who abuse alcohol and are antisocial tend to be more temperamental (Ramchandani et al., 2011). Teenage children communicate ineffectively; express problems through internalized behavior; and frequently engage in behaviors such as early sex, alcohol use, drug use, and cigarette smoking (Mares, van der Vorst, Engels, \& Lichtwarck-Aschoff, 2011). Generally speaking, the physical and mental health consequences for families, peers, and friends also appear to be substantially negative (O'Farrell \& Clements, 2012). For men who engage in such behaviors the consequences to their mental and physical health can be dire. For example, depression and anxiety are worse among male drinkers than nondrinkers (Assari, 2014). Depression in men can also have more tragic consequences than just substance abuse. Men are four times as likely as women to be successful at suicide, though women are more likely to experience suicidal ideation and attempts (Addis, 2008).

In some cases, disclosure of mental health issues is a major barrier to improving men's mental health. Consider, for example, PTSD following adverse childhood experiences (ACEs). Five percent to 15 percent of men and 15 percent to 25 percent of women experienced sexual abuse as children; 2012 estimates suggested that 10 percent of girls and 9 percent of boys were abused physically, sexually, or psychologically (HHS, 2012). However, evidence of potential gender differences in the relationship between ACEs and PTSD is mixed. Some studies suggest that women are more likely to experience PTSD after ACEs, even after accounting for the higher ACE prevalence rate for girls. Yet, other studies have found no gender difference in the association between ACEs and PTSD (see Contractor et al., 2013, for a review). Men may be at higher risk for other mental health issues associated with ACEs, particularly if disclosure is a protective factor against such problems. Male ACE victims disclose being abused far less often than female victims. In fact, Easton (2012) reported that fewer than 25 percent of boys disclose their victimhood at the time of abuse, compared with more than 60 percent of girls. Lifetime reporting for males also lags behind that of females. Fewer than 50 percent of male survivors have ever disclosed their abuse, compared with more than 70 percent of female survivors (Ullman \& Filipas, 2005). This may be one reason why the impact of abuse can have longer lasting mental health effects for men than for women (Ullman \& Filipas, 2005).

\section{Diagnostic and Clinical Issues}

As we noted earlier, mental health problems are often expressed differently in men and women. Again, we turn to depression as an example. The medical model of mental health suggests that depression is a disease in which the symptoms are expressed similarly across sociodemographic characteristics, such as gender. Yet, such a model ignores a person-in-environment (PIE) model of mental health (Addis, 2008; Nolen-Hoeksema, 2008). For example, several studies have suggested that men express depressive mood (or negative affect) through externalized behaviors - a result that has been found in various studies (see Furman, 2013, for a full discussion). This is in contrast to the typical experiences of women, who often express depression 
through internalized behaviors or somatic symptoms (see Addis, 2008; Addis \& Mahalik, 2003; and Eaton et al., 2011, for full discussions of these issues). The National Institute of Mental Health (NIMH, 2005) indicated that sadness, worthlessness, and guilt are more strongly associated with depression in women but often do not manifest themselves as symptoms in men. Instead, the most common symptoms of depression in men are exhaustion, irritability, decreased interest in normally pleasurable activities, and restlessness. Yet the acknowledgment of these differences and their integration into clinical practice has been slow, due in part to the medical model's prevalence in education and diagnosis (that is, the use of the Diagnostic and Statistical Manual of Mental Disorders [DSM] [American Psychiatric Association, 2013]) and gendered assumptions about depression.

The disconnect between the medical and PIE models of mental health is evident when considering the standardized assessment instruments used to diagnose depression. One online depression assessment provided by the American Psychiatric Association (n.d.) on its DSM-5 Web site, the PROMIS Emotional Distress-Depression-Short Form, includes questions about self-worth; outlook; helplessness; and feelings of sadness, failure, depression, unhappiness, and hopelessness; but it does not include any questions about externalizing behaviors, such as drinking, antisocial behavior, or somatic symptoms, which might manifest themselves more frequently in men. In contrast, some scales, like the Masculine Depression Scale proposed by Magovcevic and Addis (2008), appear to do a better job of capturing the experiences of depressed men with measures focusing on both internalized and externalized symptoms.

\section{Sources of Poor Mental Health in Men}

Although we know more about the predictors of mental health issues in women than men, some similarities and differences in the antecedents to such problems have been identified. Although mental health problems result from a complex interplay of genetics, biology, and environment, it appears that any biological foundation for gender differences is weak (Addis, 2011). The lack of real gender differences in the biological risk for mental health problems suggests that social and environmental factors may do a better job of explaining the gender gap in mental health (Addis \& Mahalik, 2003).
For example, physical health issues, interpersonal problems with friends and family, traumatic life events, the stress from caregiving, and role strain are more strongly associated with depressive symptoms in women than men. Meanwhile, unstable employment (that is, unemployment or underemployment), everyday stress, childhood loss, and low self-esteem tend to be more strongly associated with mental health problems in men than women. In some cases, stressors such as childbirth, social factors like a lack of social support, or characteristics like emotional vulnerability and coping style have similar influences on men's and women's mental health (see Harkness et al., 2010, for a comprehensive review of these issues). This research suggests that it is necessary for social workers to understand the unique and common risk factors for poor mental health among men and how they compare with those for women.

Emerging societal trends and current events may also contribute to poor mental health in men. Several examples are worth noting. First, as men have taken more caregiving responsibility in families, they are reporting higher levels of work-family conflict than in the past and report more conflict than women in dual-earner families (Aumann, Galinsky, \& Matos, 2011). Traditional gender norms that suggest men should be the breadwinner, coupled with more contemporary norms of being a good father/husband/partner, generate substantial conflict for men and can affect their psychological well-being-whereas women face the converse challenge (Kaufman, 2013). Second, job insecurity can be a major mental health issue for men. The Great Recession, which disproportionately affected men, underscores the precarious economic position of many American men and families (Elsby, Hobijn, \& Sahin, 2010). Third, a trend toward smaller or even absent social support networks, particularly among men, means that they have few, if any, informal outlets in which to discuss their troubles and problems (Way, 2011). Finally, recent military deployments and homecomings have shown that military men, many of whom have families, are strongly affected by military actions. These issues may be particularly prevalent among nonprofessional soldiers, like National Guardsmen, who have limited access to the services provided by the U.S. Department of Defense and Veterans Affairs (VA) postdeployment (Park, 2011). Taken together, these examples suggest that social workers 
should be aware of cultural and social trends that may negatively affect men, women, and families in unique and sometimes gendered ways.

\section{SOCIAL WORK WITH MEN}

\section{How Can We Help Men?}

Compared with other helping professions, social workers often interact with individuals outside the typical clinical office setting. Social workers are commonly employed in the child welfare system, hospitals, prisons, and elsewhere. This is advantageous because, unlike other helping professionals, social workers have the opportunity to work with men outside of the traditional clinical setting, which should be viewed as a strength and benefitespecially when considering the context of men's help-seeking behaviors. Furthermore, social work values may be a benefit in helping men, particularly those who adhere to masculine norms. It is within this context that we discuss the barriers to men's help seeking and how social workers can help men in seeking help.

Hegemonic masculine norms suggest that men should be self-reliant, problem-free, strong, brave, and emotionless (Addis, 2008). These powerful norms serve as a barrier to seeking help for a myriad of issues, including mental health difficulties. Among heteronormative men, these norms can also lead many to feel that they may be mislabeled as "gay" because they may require help for a problem. Although heteronormative and hegemonic masculine norms are problematic for a variety of reasons, they remain very real in the lives of many men and should be handled delicately by social workers working with male clients (Addis, 2011; Rochlen, McKelley, \& Pituch, 2006). Rochlen and colleagues (2010) noted other key help-seeking barriers, including the opinion among many hegemonic men that depression is normative, happiness is not a masculine virtue, and control is needed in all situations.

Despite the temptation to do so, we caution that traditional masculine attitudes should not be automatically labeled as negative but can sometimes be strengths in assisting men to seek help. Masculine norms, such as being action oriented, problem solving, and goal focused are often beneficial in therapeutic settings. Courtenay (2011) found that the goal orientation of masculine men leads to relatively high success rates in smoking cessation programs. A study of depressed men in the United Kingdom showed that many men feel that reestablishing their masculinity is a key part of their recovery (Emslie, Ridge, Ziebland, \& Hunt, 2006). Exactly how masculine norms can be used with men, however, is not well known and should be a topic of future research.

As noted earlier, researchers and clinicians should also be aware that men and women may express mental health issues differently. Failure to recognize these differences may lead gatekeepers to unwittingly turn away help-seeking men. In addition, clinicians who are not well attuned to these gender differences may sometimes misdiagnose men or fail to diagnose men who meet appropriate diagnostic criteria. For example, Afifi (2007) noted that women are more likely to get an MDD diagnosis than men with the same score on standardized diagnostic instruments, suggesting that gendered notions of practitioners may influence their clinical judgments. As a result, social workers should be acutely aware of the symptoms associated with mental health issues in men, along with their own potential biases against diagnosing men.

However, we also caution clinicians and researchers that men should not be viewed as a homogeneous group. Help-seeking behaviors and attitudes likely differ across men (Addis \& Mahalik, 2003)— although very little research has addressed this possibility. Some evidence does exist, however, on effective strategies for forming good therapeutic alliance with men. Courtenay (2011) noted the importance of humanizing issues for men, noting that clinicians should emphasize the point that vulnerability and illness are a natural part of life. Similarly, Rochlen and colleagues (2010) suggested that contextualizing mental health issues as medical conditions is often effective at getting men to overcome their reluctance to participate in counseling (that is, if you had a broken leg, you would see a doctor). Given this context, effective communication that recognizes the unique ways in which men communicate is a critical aspect of helping men who are seeking help or are reluctant to see a mental health professional.

Social workers ought to be inviting and welcoming toward male clients. Social workers should show that they trust men, are happy they are seeking help, want to understand their unique problems and issues, and will meet them where they are. The importance of a welcoming physical environment is well illustrated by an example from social work 
practice with fathers. Many potential male clients reported that the feminine decor of a clinician's office or social services agency sent them the message that they were not wanted there, putting up a serious and unnecessary roadblock to their participation (Lee, Yelick, Brisebois, \& Banks, 2011). The lack of male staff and clinicians in social work practice can also be problematic. In some cases, men prefer to be counseled by other men. For example, Courtenay (2011) reported that help seeking was more likely in highly masculine men if they could be seen by another man. A serious problem in the profession is the lack of male social workers. Estimates from the 2012 American Community Survey (U.S. Census Bureau, 2012) showed that only 20 percent of social workers are male. Other men, however, will prefer a female mental health professional. Female social workers may be seen as "safer," particularly if men feel that they have to maintain masculine attitudes and hegemonic norms around other men.

\section{Research Implications}

We would be remiss if we did not discuss the need for additional research on men's mental health. Although significant research has been done regarding depression and anxiety in men, gaps in the literature remain. To date, researchers (and possibly clinicians) adhere to a model that emphasizes how masculinity informs the expression of symptoms and acts as a barrier to help-seeking behaviors (see Addis, 2008, for a full discussion). To be sure, this is a critical aspect of understanding men's mental health-but little research has addressed its role in improving client outcomes, variability in masculine attitudes, or the mechanisms between masculine attitudes and mental health issues. Greater insights into these areas can help researchers and clinicians understand the nuances within the male gender. One way to understand within-gender differences is by considering whether mental health symptoms and help-seeking attitudes differ by race and ethnicity, socioeconomic status, sexuality, and other sociodemographic characteristics. Furthermore, research needs to address mental health problems beyond depression and anxiety. It is clear that the vast majority of research on men's mental health and gender differences in mental health has addressed these two issues. Yet we know relatively little about how gender relates to other mental health issues and withingender differences that may exist with these issues.
More clinical research is also key in understanding men's mental health. Good evidence-based and evidence-informed practice is based on research that addresses a particular issue or concern (Bellamy, 2009). As we have noted, the differences between men and women in how mental health conditions manifest themselves symptomatically can influence diagnoses. Studies that address diagnostic criteria that better capture mental health issues in men and women are necessary. A second area of potential investigation is how different therapeutic techniques may prove more useful with men. This could be important, particularly in the context of adherence or lack of adherence to masculine norms. Furthermore, addressing men's clinical outcomes, compared with those of women and among men, may help us understand why men may feel that clinicians are not competent to help with their problems.

Finally, comprehending help-seeking barriers and how they might be overcome is a critical point for future research. Simply put, many of the points we have made are moot if men as a whole remain resistant to mental health care. Although the research on men's help seeking has identified reasons why men are hesitant to see mental health professionals, we know very little about how to best assist men in seeking help. For example, a recent NIMH campaign targeting traditionally masculine men with negative help-seeking attitudes (Real Men, Real Depression) was relatively unsuccessful because many men felt the name was "cheesy," demeaned their existing view of masculinity, and existed only to drum up business for clinicians. The lessons from such a campaign are clear: Social workers need to combine their professional skill set and values with the understanding that they ought to meet men where they are and use masculinity as a strength. Given the profession's core values of respect and dignity for all individuals and selfdetermination, social workers may be in a better position than other helping professionals to engage men in mental health and social services. Furthermore, researchers could also address our assertion that social workers can increase help seeking in men by engaging them in nonclinical settings like schools, the child welfare system, health care settings, and social services agencies (that is, the VA, public assistance offices, and so forth). This research may prove particularly useful to social work practitioners across the various settings in which they work. 


\section{CONCLUDING THOUGHTS}

We have provided a brief overview of why and how social workers should engage with men. Our discussion was limited to mental health issues, with a particular emphasis on depression, anxiety, and PTSD. We did not discuss other related problems, such as physical health, homelessness, incarceration, and economic well-being, which are salient issues that social workers also address. Given the breadth of these topics, they ought to be the foci of other reviews.

It is clear that more research on the mental health of men is needed. Simply stated, very little is known about the gender-specific causes and consequences of men's mental health. Even less empirical research exists to explain why many men are more averse to help seeking than are women or how to encourage men to seek mental health assistance. These are important issues that ought to be confronted by social work researchers, particularly given social work's predilection for a systemic view, as represented by the PIE model. Unfortunately, the literature on helping men is small and disjointed.

Nevertheless, we argue that to help individuals, families, and communities, social workers should take a systemic approach in which the worth and dignity of all individuals is recognized for the betterment of society as a whole. Our main premise is that helping men will help women, children, and communities, as women, children, and men themselves interact with men on a daily basis as sons, fathers, brothers, uncles, friends, coworkers, employers, employees, teachers, and so forth. Social workers have a vested stake in good mental health for men and should make the necessary investments, as a profession, to take seriously the mental health concerns of women, children, and men. As gender roles and attitudes change in the United States, the time has come to increase social work's recognition of men as a special group that interacts with, influences, and affects the outcomes of others, including members of marginalized and vulnerable groups. Because social workers are uniquely positioned to address the various challenges surrounding men's mental health, it is incumbent on them to do so. SW

\section{REFERENCES}

Acevedo, B. P., Lowe, S. R., Griffin, K. W., \& Botvin, G. J. (2013). Predictors of intimate partner violence in a sample of multiethnic urban young adults. Journal of Interpersonal Violence, 28, 3004-3022.
Addis, M. E. (2008). Gender and depression in men. Clinical Psychology: Science and Practice, 15(3), 153-168.

Addis, M. E. (2011). Invisible men: Men's inner lives and the consequences of silence. New York: Henry Holt.

Addis, M. E., \& Mahalik, J. R. (2003). Men, masculinity, and the contexts of help seeking. American Psychologist, 58(1), 5-14.

Afifi, M. (2007). Gender differences in mental health. Singapore Medical Journal, 48(5), 385-391.

American Psychiatric Association. (2013). Diagnostic and statistical manual of mental disorders (5th ed.). Washington, DC: Author.

American Psychiatric Association. (n.d.). Online assessment measures. Washington, DC: Author. Retrieved from http://www.psychiatry.org/practice/dsm/dsm5/ online-assessment-measures

Assari, S. (2014). Separate and combined effects of anxiety, depression and problem drinking on subjective health among black, Hispanic and non-Hispanic white men. International Journal of Preventive Medicine, 5(3), 269-279.

Aumann, K., Galinsky, E., \& Matos, K. (2011). The new male mystique. National Study of the Changing Workforce, Families and Work Institute. Retrieved from http:// www.familiesandwork.org/site/research/reports/ main.html

Bellamy, J. L. (2009). A national study of male involvement among families in contact with the child welfare system. Child Maltreatment, 14(3), 255-262.

Connell, R. W., \& Messerschmidt, J. W. (2005). Hegemonic masculinity: Rethinking the concept. Gender \& Society, 19, 829-859.

Contractor, A. A., Layne, C. M., Steinberg, A. M., Ostrowski, S. A., Ford, J. D., \& Elhai, J. D. (2013). Do gender and age moderate the symptom structure of PTSD? Findings from a national clinical sample of children and adolescents. Psychiatry Research, 210, 1056-1064.

Courtenay, W. H. (2011). Dying to be men. New York: Routledge.

Easton, S. D. (2012). Understanding adverse childhood experiences (ACE) and their relationship to adult stress among male survivors of childhood sexual abuse. Journal of Prevention \& Intervention in the Community, 40(4), 291-303.

Eaton, W. W., Chen, C. Y., \& Bromet, E. J. (2011). Epidemiology of schizophrenia. In M. T. Tsuang, M. Tohen, \& P. Jones (Eds.), Textbook of psychiatric epidemiology (3rd ed., pp. 263-287). New York: John Wiley \& Sons.

Elsby, M. W., Hobijn, B., \& Sahin, A. (2010). The labor market in the Great Recession (No. 15979). Cambridge, MA: National Bureau of Economic Research.

Emslie, C., Ridge, D., Ziebland, S., \& Hunt, K. (2006). Men's accounts of depression: Reconstructing or resisting hegemonic masculinity? Social Science \& Medicine, 62, 2246-2257.

Furman, R. (2013). Social work practice with men at risk. New York: Columbia University Press.

Harkness, K. L., Alavi, N., Monroe, S. M., Slavich, G. M., Gotlib, I. H., \& Bagby, R. M. (2010). Gender differences in life events prior to onset of major depressive disorder: The moderating effect of age. Journal of Abnormal Psychology, 119, 791-803.

Hendrick, V., Altshuler, L. L., Gitlin, M. J., Delrahim, S., \& Hammen, C. (2000). Gender and bipolar illness. Journal of Clinical Psychiatry, 61, 393-396.

Kaufman, G. (2013). Superdads: How fathers balance work and family in the 21st century. New York: New York University Press.

Lee, S. J., Yelick, A., Brisebois, K., \& Banks, K. L. (2011). Low-income fathers' barriers to participation in family 
and parenting programs. Journal of Family Strengths, 11(1), Article 12.

Magovcevic, M., \& Addis, M. E. (2008). The Masculine Depression Scale: Development and psychometric evaluation. Psychology of Men \& Masculinity, 9(3), 117-132.

Mares, S. H., van der Vorst, H., Engels, R. C., \& Lichtwarck-Aschoff, A. (2011). Parental alcohol use, alcohol-related problems, and alcohol-specific attitudes, alcohol-specific communication, and adolescent excessive alcohol use and alcohol-related problems: An indirect path model. Addictive Behaviors, 36, 209-216.

McLean, C. P., Asnaani, A., Litz, B. T., \& Hofmann, S. G. (2011). Gender differences in anxiety disorders: Prevalence, course of illness, comorbidity and burden of illness. Journal of Psychiatric Research, 45, 1027-1035.

Mossakowski, K. N. (2013). Disadvantaged family background and depression among young adults in the United States: The roles of chronic stress and self-esteem. Stress and Health. Advance online publication.

National Institute of Mental Health. (2005). Real men, real depression. Washington, DC: National Institutes of Health.

Nolen-Hoeksema, S. (2008). Emotion regulation and psychopathology: The role of gender. Annual Review of Clinical Psychology, 8, 161-187.

O'Farrell, T. J., \& Clements, K. (2012). Review of outcome research on marital and family therapy in treatment for alcoholism. Journal of Marital and Family Therapy, 38(1), 122-144.

Park, N. (2011). Military children and families: Strengths and challenges during peace and war. American Psychologist, 66(1), 65-72

Parker, G., \& Brotchie, H. (2010). Gender differences in depression. International Review of Psychiatry, 22, 429-436.

Piccinelli, M., \& Homen, F. G. (1997). Gender differences in the epidemiology of affective disorders and schizophrenia. New York: World Health Organization.

Piccinelli, M., \& Wilkinson, G. (2000). Gender differences in depression: Critical review. British Journal of Psychiatr $\gamma, 177,486-492$

Ramchandani, V. A., Stangl, B. L., Vatsalya, V., Cooke, M. E., Zametkin, M., Zimmermann, U. S., et al. (2011). Determinants of intravenous alcohol selfadministration and pharmacodynamics responses: Human laboratory studies. Alcoholism: Clinical and Experimental Research, 35(6), 307A.

Rochlen, A. B., McKelley, R., \& Pituch, K. (2006). A preliminary examination of the Real Men, Real Depression campaign. Psychology of Men and Masculinity, 7(1), 1-13.

Rochlen, A. B., Paterniti, D. A., Epstein, R. M., Duberstein, P. R., Willeford, L. C., \& Kravitz, R. L. (2010). Barriers in diagnosing and treating men with depression: A focus group report. American Journal of Men's Health, 4(2), 167-175.

Ullman, S. E., \& Filipas, H. H. (2005). Gender differences in social reactions to abuse disclosures, post-abuse coping, and PTSD in child sexual abuse survivors. Child Abuse and Neglect, 29, 767-782.

U.S. Census Bureau. (2012). 2012 American Community Survey. Washington, DC: Author.

U.S. Department of Health and Human Services. (2012). Child maltreatment: 2011. Washington, DC: Children's Bureau.

Way, N. (2011). Deep secrets. Cambridge, MA: Harvard University Press.
World Health Organization. (2007). Gender disparities in mental health. New York: United Nations.

Kevin Shafer, PhD, is assistant professor, and Douglas Wendt, BS, is graduate research assistant, School of Social Work, Brigham Young University, Provo, UT. Address correspondence to Kevin Shafer, School of Social Work, Bringham Young University, 2190 JFSB, Provo, UT 84602; e-mail: kevin_shafer@byu.edu.

Original manuscript received August 1, 2014 Accepted September 2, 2014

Advance Access Publication January 14, 2015

\section{NASW PRESS POLICY ON ETHICAL BEHAVIOR}

7 he NASW Press expects authors to adhere to ethical standards for scholarship as articulated in the NASW Code of Ethics and Writing for the NASW Press: Information for Authors. These standards include actions such as

- taking responsibility and credit only for work they have actually performed

- honestly acknowledging the work of others

- submitting only original work to journals

- fully documenting their own and others' related work.

If possible breaches of ethical standards have been identified at the review or publication process, the NASW Press may notify the author and bring the ethics issue to the attention of the appropriate professional body or other authority. Peer review confidentiality will not apply where there is evidence of plagiarism.

As reviewed and revised by NASW National Committee on Inquiry (NCOI), May 30, 1997

Approved by NASW Board of Directors, September 1997 